\title{
$\beta$-transducin repeat-containing E3 ubiquitin protein ligase inhibits migration, invasion and proliferation of glioma cells
}

\author{
JUN LIANG $^{1,2^{*}}$, WEI-FENG WANG ${ }^{2,3^{*}}$, SHAO XIE $^{1,2}$, XIAN-LI ZHANG $^{2,3}$, WEI-FENG QI ${ }^{2,3}$, \\ XIU-PING ZHOU ${ }^{1,2}$, JIN-XIA HU ${ }^{1,2}$, QIONG SHI ${ }^{1,2}$ and RU-TONG YU ${ }^{1,2}$ \\ ${ }^{1}$ Department of Neurosurgery; ${ }^{2}$ Laboratory of Neurosurgery, Affiliated Hospital of Xuzhou Medical College; \\ ${ }^{3}$ Department of Neurosurgery, Graduate School, Xuzhou Medical College, Xuzhou, Jiangsu 221002, P.R. China
}

Received November 28, 2015; Accepted May 11, 2017

DOI: $10.3892 / \mathrm{ol} .2017 .6533$

\begin{abstract}
E3 ubiquitin protein ligase $(\beta$-TrCP) serves as the substrate recognition subunit for the Skp1-Cullin1-F-box protein E3 ubiquitin ligase, which recognizes the double phosphorylated DSG $(\mathrm{X})_{2+\mathrm{n}} \mathrm{S}$ destruction motif in various substrates that are essential for numerous aspects of tumorigenesis and regulates several important signaling pathways. However, the biological significance of $\beta$-TrCP in glioma progression remains largely unknown. A previous study by the authors demonstrated that the levels of $\beta$-TrCP protein expression in brain glioma tissues were significantly lower compared with non-tumorous tissues and that higher grades of gliomas exhibited lower levels of $\beta$-TrCP expression in comparison with lower glioma grades. In addition, low $\beta$-TrCP expression was associated with poor prognosis in patients with glioma. Subsequently, the present study aimed to investigate the effect of $\beta-\mathrm{TrCP}$ on migratory, invasive and proliferative abilities of glioma cells. $\beta$-TrCP plasmids were transfected into cultured U251 and U87 glioma cells, and changes in migration, invasion and proliferation were analyzed using wound healing, Transwell and EdU assays. It was identified that the overexpression of $\beta$-TrCP inhibited migration, invasion and proliferation in glioma cells. In summary, these results indicate that $\beta$-TrCP may serve a protective role against the progression of glioma by suppressing cell migration, invasion and proliferation. The potential mechanism of $\beta$-TrCP I glioma cells requires additional investigation.
\end{abstract}

Correspondence to: Professor Ru-Tong Yu, Department of Neurosurgery, Affiliated Hospital of Xuzhou Medical College, 99 West Huai-hai Road, Xuzhou, Jiangsu 221002, P.R. China

E-mail: yu.rutong@163.com

\section{*Contributed equally}

Key words: $\beta$-transducin repeat-containing E3 ubiquitin protein ligase, migration, invasion, proliferation, glioma cells

\section{Introduction}

Gliomas are the most frequent and aggressive malignant tumors, with an average survival time of 12 months (1-3). A major cause of the failure of conventional treatments is the highly invasive and diffusively infiltrative nature of these tumors (4,5). Despite advances in surgery and adjuvant therapy, the survival time of patients with malignant glioma has changed little over the past decades $(6,7)$. With the development of molecular biology, gene therapy is becoming the focus of tumor therapy. Therefore, identifying molecular mechanisms and novel tumor therapeutic targets is critical and necessary for this incurable cancer.

$\beta$-transducin repeat-containing protein $(\beta$-TrCP), as the substrate recognition subunit for the E3 ubiquitin ligases, utilizes seven WD40 repeats to interact with substrates phosphorylated within the DSG $(\mathrm{X})_{2+\mathrm{n}} \mathrm{S}$ destruction motifs and is involved in the degradation of numerous proteins in cell signaling and cell cycle regulation (8-10). $\beta$-TrCP is involved in major regulatory mechanisms, including cell cycle progression, metabolism, development and immunity (11-14). Notably, two $\beta$-TrCP proteins are expressed in humans. $\beta$-TrCP1 is encoded by BTRC, and $\beta$-TrCP 2 encoded by FBXW11, also known as HOS or $\beta$-TRCP2 $(15,16)$. The ubiquitin proteasome pathway serves a pivotal role in controlling the degradation of the majority of regulatory proteins in mammalian cells $(17,18)$ and regulates a number of cellular processes by facilitating the timely destruction of key regulatory proteins by the $26 \mathrm{~S}$ proteasome complex (19). In this pathway, protein ubiquitination involves the concerted action of the E1 ubiquitin-activating enzyme, an E2 ubiquitin-conjugating enzyme and an E3 ubiquitin-protein ligase, of which delivers multiple ubiquitin molecules to the target protein (20-22).

Diverse $\beta$-TrCP substrates involved in different normal and malignant pathways have been identified, includingBMI-1 (23), I $x$ B (24), $\beta$-catenin $(25,26)$, vascular endothelial growth factor receptor 2 (VEGFR2) (27), metastasis suppressor protein 1 (MTSS1) (28), Emi1 (29), SNAI1 (30), and M-phase inducer phosphatase 1 (Cdc25A) (9). Zhong et al (28) reported that $\beta$-TrCP targetsMTSS1 for ubiquitination-mediated destruction, to promote breast and prostate cancer cell proliferation and migration. However, Shaik et al (27) demonstrated that $\beta$-TrCP suppresses angiogenesis and thyroid cancer cell migration by 
promoting ubiquitination and destruction of VEGFR2. In addition, $\beta$-TrCP may inhibit growth and invasiveness of lung cancer cells (31). Therefore, the roles of $\beta$-TrCP are different in different types of tumors.

Previous studies by the authors have demonstrated that $\beta$-TrCP protein expression levels were significantly lower in glioma compared with non-tumorous human brain tissues and that low $\beta$-TrCP expression indicated poor prognosis in patients with glioma (32). In the present study, it was additionally observed that $\beta$-TrCP affected migration, invasion and proliferation of human glioma cells.

\section{Materials and methods}

Antibodies and reagents. The rabbit polyclonal anti- $\beta$-TrCP antibody was purchased from Abcam (ab71753; 1:500; Cambridge, UK). The rabbit polyclonal anti-Flag antibody was purchased from EarthOx Life Sciences (EO22230; 1:2,000; Millbrae, CA, USA). The rabbit monoclonal anti- $\beta$-actin antibody was purchased from EMD Millipore (04-1116; 1:2,000; Billerica, MA, USA).

Cell culture and plasmid transfection. Human glioma U251 and U87 cell lines were purchased from Shanghai Cell Bank of the Type Culture Collection Committee of the Chinese Academy of Sciences (Shanghai, China). The cells were cultured in DMEM/F-12 media (Gibco; Thermo Fisher Scientific, Inc., Waltham, MA, USA) supplemented with $10 \%$ fetal bovine serum (FBS; Evergreen Biological Engineering Co., Hangzhou, China) in a humidified incubator with $5 \%$ $\mathrm{CO}_{2}$ at $37^{\circ} \mathrm{C}$. For transfection, U251 or U87 cells were transfected with $\beta$-TrCP plasmid (1 $\mu \mathrm{g}$; plasmid 10865; Addgene, Inc., Cambridge, MA, USA) using Lipofectamine $2000^{\circledR}$ (Invitrogen; Thermo Fisher Scientific, Inc.) according to the manufacturer's specifications. U251 or U87 cells transfected with an empty plamid were used as controls.

Western blot analysis. Following $24 \mathrm{~h}$ transfection with the $\beta$-TrCP plasmid, total protein from the transfected U251/U87 cells was extracted using lysis buffer (RIPA, $1 \mathrm{ml}$; Aprotinin, $1 \mu \mathrm{l}, 2 \mu \mathrm{g} / \mathrm{ml}$; Leupeptin, (1-10) $\mu \mathrm{l}, 10-100 \mu \mathrm{M}$; Pepstatin A, $1 \mu \mathrm{l}, 1 \mu \mathrm{M}$; PMSF, $5 \mu 10.5 \mathrm{mM}$; Benzamidine, $1 \mu \mathrm{l}, 4 \mathrm{mM}$; DTT, $1 \mu 1,1 \mathrm{mM}$ ) consisting of protease inhibitors. The protein lysates $(80 \mu \mathrm{g})$ were subjected to $10 \%$ SDS-PAGE, then transferred to polyvinylidene fluoride (PVDF) membrane (Merck KGaA, Darmstadt, Germany), and probed with primary antibodies $(\beta$-TrCP, 1:500; $\beta$-actin, 1:2,000; anti-Flag, 1:2,000) for target bands at $4^{\circ} \mathrm{C}$ overnight for blocking and secondary antibodies (7074; 1:4,000; Cell Signaling Technology, Inc., Danvers, MA, USA) at room temperature for $2 \mathrm{~h}$. Bound antibodies were detected by the Pierce ECL Plus Western Blotting substrate (Thermo Fisher Scientific, Inc.) and exposed to X-ray films. The PVDF membranes were washed (3 times for $15 \mathrm{~min}$ each) using washing buffer (TBST) following incubation with antibodies. Band densities were quantified using Image $\mathrm{J}$ software (1.42q, National Institutes of Health, Bethesda, MD, USA). The relative amount of proteins was determined by normalizing the densitometry value of interest to that of the internal loading control. Western blotting was performed for three times.
Wound healing assay. A total of $24 \mathrm{~h}$ following transfection with $\beta$-TrCP plasmid $\left(1.5 \times 10^{5}\right.$ cells per hole $)$, a rectangular lesion was created using a plastic pipette tip and the monolayer was rinsed twice for $1 \mathrm{~min}$ with PBS and incubated in serum-free media [Dulbecco's modified Eagle's medium (DMEM); Gibco; Thermo Fisher Scientific, Inc.] at $37^{\circ} \mathrm{C}$ for $24 \mathrm{~h}$. Subsequently, 5 randomly selected fields at the lesion border were acquired under an inverted microscope (magnification, x100; Olympus Corporation, Tokyo, Japan). U251 or U87 cells transfected with empty plasmids were used as controls.

Transwell invasion assay. Cell invasion assays were performed using a Transwell system that incorporated a polycarbonate filter membrane with a diameter of $6.5 \mathrm{~mm}$ and pore size of $8 \mu \mathrm{m}$ (Corning Incorporated, Corning, NY, USA), according to the manufacturer's protocol. To assess invasion, filters were precoated with $10 \mu \mathrm{g}$ Matrigel (BD Biosciences, Franklin Lakes, NJ). A pretreated cell suspension $\left(1 \times 10^{5}\right)$ in serum-free culture media (Gibco; Thermo Fisher Scientific, Inc.) was added into the inserts, and each insert was placed in the lower chamber filled with culture media containing $10 \% \mathrm{FBS}$ as a chemoattractant. Following $24 \mathrm{~h}$ incubation at $37^{\circ} \mathrm{C}$, the non-invasive cells were removed from the upper chamber. The filters were fixed with methanol for $15 \mathrm{~min}$ and stained with a $0.1 \%$ crystal violet solution at $37^{\circ} \mathrm{C}$ for $10 \mathrm{~min}$. A total of 5 fields of adherent cells in each well were randomly photographed under an inverted microscope (magnification, x100; IX71; Olympus, Japan) and counted. The same experimental design was used for the migration experiments, except that filters were not precoated with Matrigel. U251 or U87 cells transfected with empty plamids were used as controls.

5-ethynyl-2'-deoxyuridine (EdU) assay. The effects on proliferative ability of U251 and U87 cells was measured by EdU incorporation assay using the EdU assay kit (Guangzhou RiboBio Co., Ltd., Guangzhou, China) subsequent to $\beta$-TrCP plasmids transfection according to the manufacture's protocol. Briefly, U251 or U87cells at $4 \times 10^{3}$ cells/well were cultured in triplicate in 96-well plates and transfected with $\beta$-TrCP plasmids for $24 \mathrm{~h}$. The cells were subsequently exposed to $50 \mu \mathrm{M}$ EdU for an additional $2 \mathrm{~h}$ at $37^{\circ} \mathrm{C}$. The cells were fixed with $4 \%$ formaldehyde for $30 \mathrm{~min}$ at room temperature and treated with $2 \mathrm{mg} / \mathrm{ml}$ glycine to neutralize the formaldehyde, then treated with $0.5 \%$ Triton X-100 for $15 \mathrm{~min}$ at room temperature for permeabilization. Following 3 washes with PBS for $15 \mathrm{~min}, 100 \mu \mathrm{l} 1 \mathrm{x}$ Apollo reaction cocktail (Guangzhou RiboBio Co., Ltd.) was added into each well for $30 \mathrm{~min}$. Subsequently, the DNA contents of the cells in each well were stained with $100 \mu 1$ 1X Hoechst 33342 (Beyotime Institute of Biotechnology, Haimen, China) for $30 \mathrm{~min}$ and visualized under a fluorescence microscope (magnification, x100; IX71; Olympus, Japan). U251 or U87 cells transfected with empty plamids were used as controls.

Statistical analysis. The SPSS package (version 16.0; SPSS, Inc., Chicago, IL, USA) was used to perform statistical analyses. To distinguish the difference between the treatment and control groups, the statistical significance was determined using Student's t-test. Data was presented as the 
A

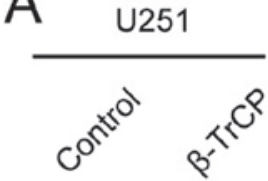

(2)

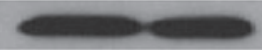

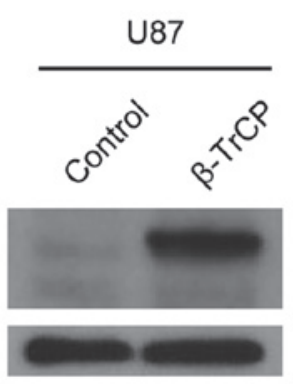
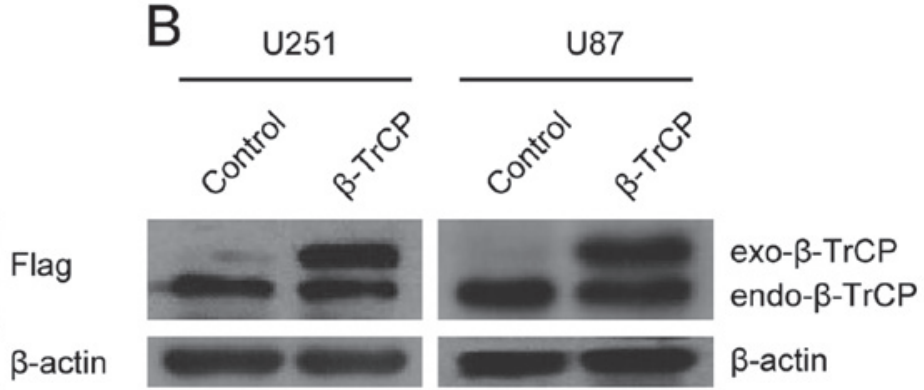

Figure 1. Western blot analysis of exogenous $\beta$-TrCP expression in U251 and U87 cells. After 24 h transfection with $\beta$-TrCP plasmids, the cells were lysed and protein extraction was performed. Western blot analysis was carried out using (A) Flag or (B) $\beta$-TrCP antibody. $\beta$-actin was used as the loading control. $\beta$-TrCP, $\beta$-transducin repeat-containing protein; exo, exogenous, endo, endogenous.

mean \pm standard error. $\mathrm{P}<0.05$ was considered to indicate a statistically significant difference.

\section{Results}

Validation of $\beta$-TrCP plasmid transfection. The effect of $\beta$-TrCP plasmid transfection was validated in U251 and U87 cells (Fig. 1A and B). The exogenous $\beta$-TrCP and endogenous $\beta$-TrCP were well-expressed when immunoblotted with anti-Flag or with anti- $\beta$-TrCP antibodies.

Effect of $\beta$-TrCP on glioma cell migration. Whether overexpression of $\beta$-TrCP affects the migration of glioma cells was examined using wound healing assay. As shown in Fig. 2A, $48 \mathrm{~h}$ after being scratched, the wound of the control group had clearly healed, and exhibited a tendency to fuse, but any evidence of healing was not observed in the $\beta$-TrCP-overexpressing group. Compared with the control group, the migratory cell numbers of the $\beta$-TrCP overexpressing group in U251 and U87 cells were decreased to $48.26 \pm 3.64$ and $58.70 \pm 2.31 \%$, respectively (Fig. 2B).

Effect of $\beta$-TrCP on glioma cell invasion. Migration and invasion are widely considered to be two closely interrelated processes. The role of $\beta$-TrCP in invasion of glioma cells was investigated using Matrigel precoated Transwell chambers. As demonstrated in Fig. $2 \mathrm{C}$, the overexpression of $\beta$-TrCP produced a significant reduction in the number of invasive cells. Compared with the control group, the number of invasive cells was reduced to $50.08 \pm 3.51$ and $42.15 \pm 2.43 \%$ in $\mathrm{U} 251$ and $\mathrm{U} 87$ cells, respectively, following $\beta$-TrCP overexpression (Fig. 2D). These results demonstrate that $\beta$-TrCP is directly involved in suppressing cell migration and invasion.

Effect of $\beta$-TrCP on glioma proliferation. Cell proliferation is an important factor in the progression of tumors, so possible changes in cell proliferation following $\beta$-TrCP overexpression were next detected by EdU assay. Following $24 \mathrm{~h}$ of transfection with $\beta$-TrCP plasmid, the U251 and U87 glioma cells were treated with the EdU reagent (Fig. 3). The numbers of positive EdU cells were counted, and the differences between different groups were analyzed. Compared with the control group, the number of proliferative cells was reduced to $44.08 \pm 6.12$ and $57.6 \pm 9.07 \%$ in U251 and U87 cells following $\beta$-TrCP overexpression, respectively (Fig. 3B and D). The results of the present study demonstrate that overexpressing $\beta$-TrCP may suppress glioma cell proliferation.

\section{Discussion}

$\beta$-TrCP is a well-characterized E3 ubiquitin ligase that is involved in the degradation of a number of proteins involved in cell signaling and cell cycle regulation (8-10). Owing to the diversity in its substrates, $\beta$-TrCP was suggested to be responsible for oncogenesis or inhibiting tumorigenesis. In colon cancer cells, $\beta$-TrCP has been demonstrated to promote ubiquitination and degradation of PHLPP1, which negatively regulate Akt signaling and promote colon cell growth (33). $\beta$-TrCP inhibition reduced prostate cancer cell growth via upregulation of the aryl hydrocarbon receptor (34). However, in lung cancer cell lines, it has been shown that the loss of $\beta$-TrCP resulted in the promotion of cell growth and invasion, possibly through the regulation of the levels of CDC25A and the matrix metalloproteinase 11 (31). $\beta$-TrCP inhibited the activity of transforming growth factor- $\beta$ in pancreatic cancer cells by decreasing Smad4 stability (35). $\beta$-TrCP suppressed angiogenesis and thyroid cancer cell migration by promoting ubiquitination and destruction of VEGFR2 (27).

However, little is known about the role of $\beta-\operatorname{TrCP}$ in the aggressive behavior of glioma. In a previous study by the authors (32), the protein expression level of $\beta$-TrCP in brain glioma tissue was detected by western blot analysis and immunohistochemistry. It was identified that the expression level of $\beta$-TrCP protein in human brain glioma samples was significantly lower compared with non-tumor tissues, and the expression level of $\beta$-TrCP in high-grade gliomas (grade III and IV) was significantly lower compared with low-grade gliomas (grade I and II). These results demonstrate that $\beta$-TrCP probably serves a role in inhibiting the growth of glioma.

Migration, invasion and proliferation are basic features of malignancies. These characteristics reflect the degree of malignancy of tumor cells. Therefore the present study investigated how $\beta$-TrCP affects migratory, invasive and proliferative abilities of glioma cells. As the previous study demonstrated that $\beta$-TrCP was expressed at low levels in glioma tissues (32). In the present study, $\beta$-TrCP was overexpressed by $\beta$-TrCP plasmid transfection prior to subsequent experiments.

The effect of $\beta$-TrCP plasmid transfection was validated in glioma cells. Exogenous $\beta$-TrCP and endogenous $\beta$-TrCP 
A

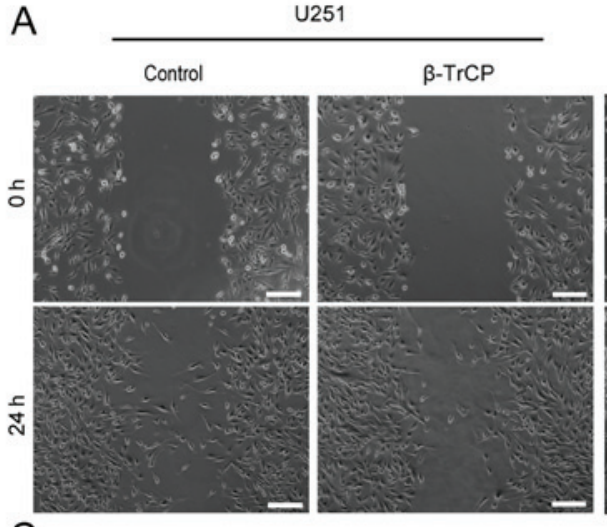

C

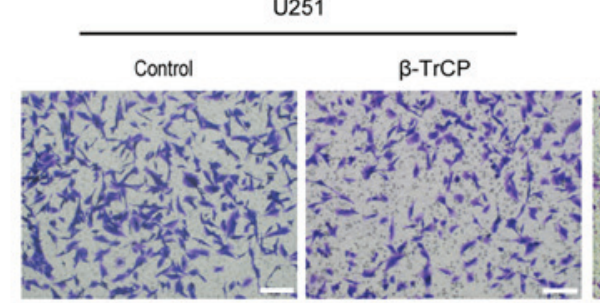

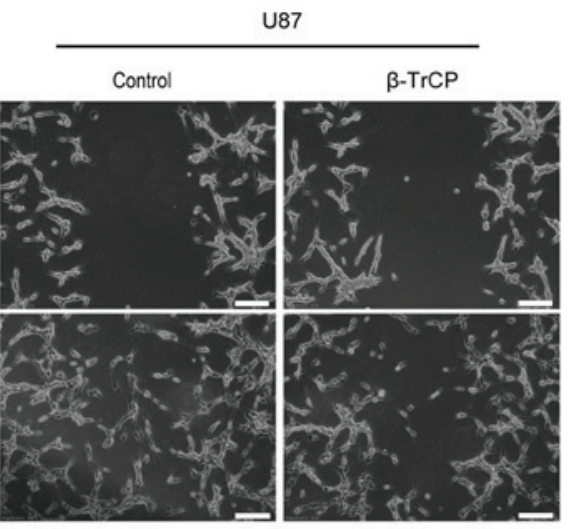

U87

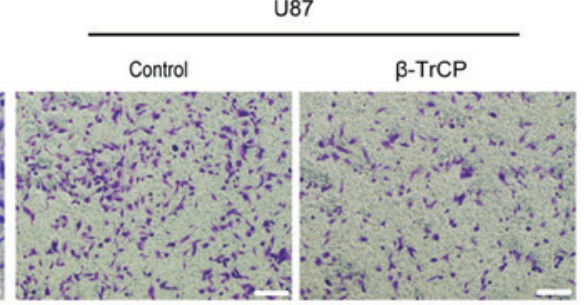

$\mathrm{B}$
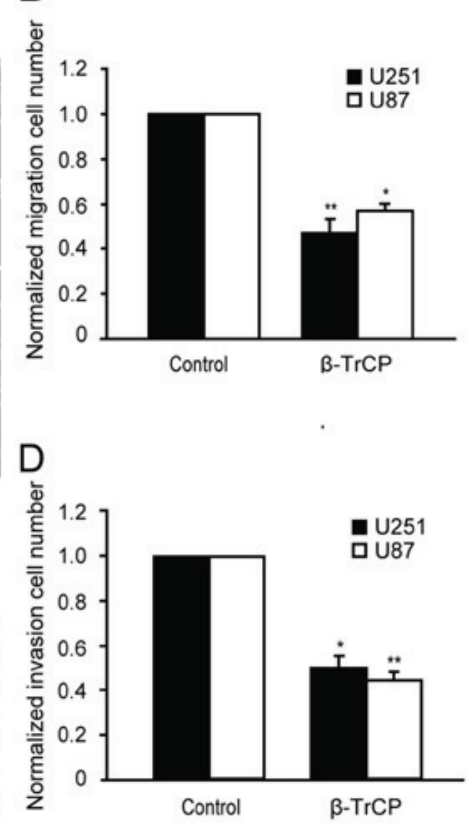

Figure 2. Overexpression of $\beta$-TrCP significantly inhibits the migratory and invasive ability of glioma cells. (A) Wound healing assay of U251 and U87 cells at 0 and $24 \mathrm{~h}$ following transient transfection with $\beta$-TrCP plasmids vs. the control vector group. Scale bar, $100 \mu \mathrm{m}$. (B) Cell migration was quantified at $24 \mathrm{~h}$. (C) Representative micrographs of U251 and U87 invasion at $24 \mathrm{~h}$ after transient transfection with $\beta$-TrCP plasmids. Scale bar, $100 \mu$ m. (D) Cell invasion was calculated from Transwell assays with Matrigel. Cell count was normalized to the vacant vector group. ${ }^{*} \mathrm{P}<0.05$, ${ }^{* *} \mathrm{P}<0.01$ vs. control. $\beta$-TrCP, $\beta$-transducin repeat-containing protein. Scale bar, $100 \mu \mathrm{m}$.
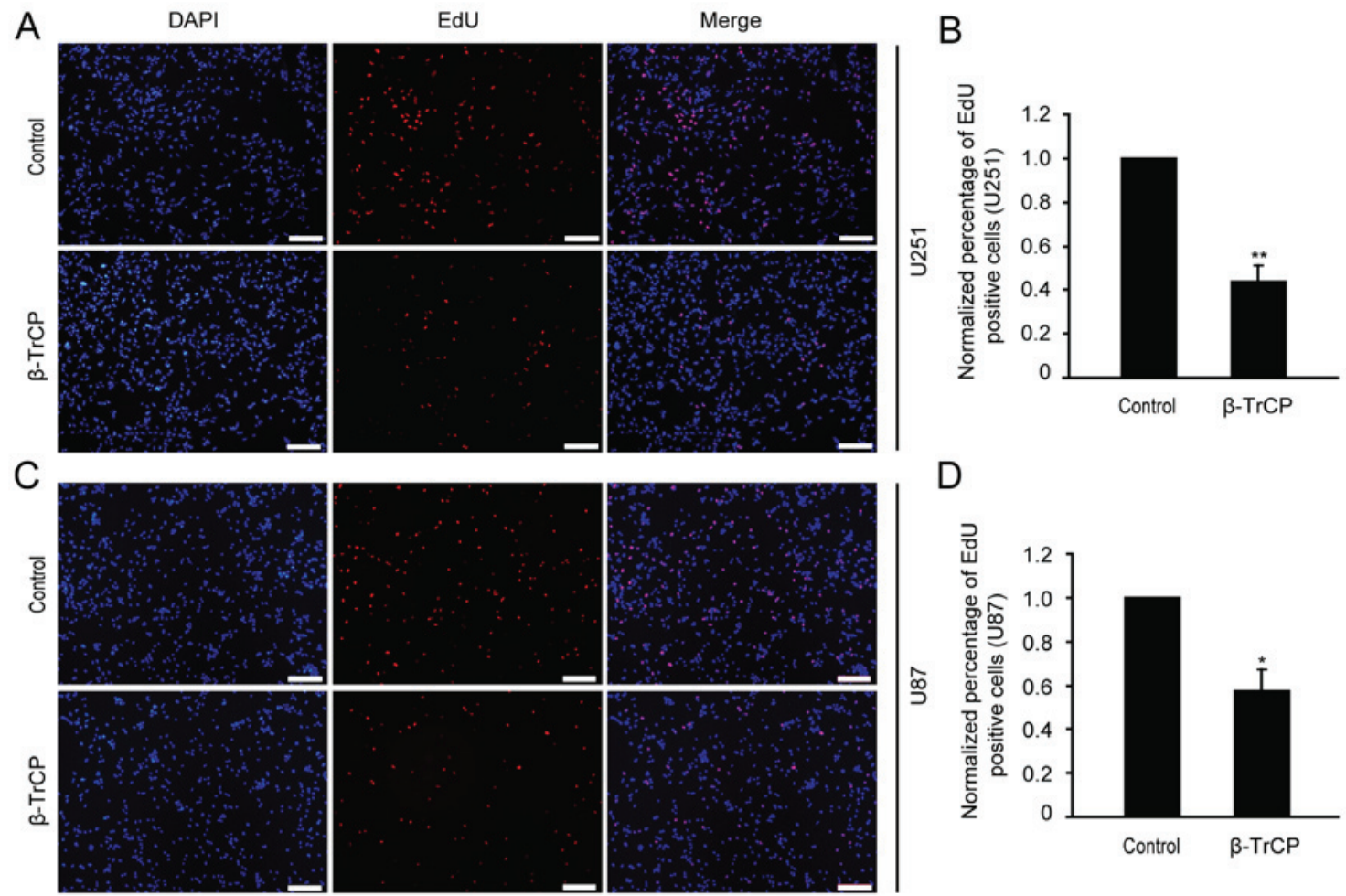

Figure 3. Overexpression of $\beta$-TrCP significantly inhibits the proliferative ability of glioma cells. Representative images of EdU positive cells: (A) U251 and (C) U87 cells. Graph presenting the changes between cells overexpressing $\beta$-TrCP and the control: (B) U251 and (D) U87 cells. * $\mathrm{P}<0.05$, ${ }^{* *} \mathrm{P}<0.01$ vs. control. $\beta$-TrCP, $\beta$-transducin repeat-containing protein. Scale bar, $100 \mu \mathrm{m}$.

were well-expressed, and this formed the basis of subsequent experiments. Subsequently, wound healing assay was used to investigate the effect of $\beta$-TrCP on glioma cell migration. It was observed that the ability of wound healing in the $\beta-\operatorname{TrCP}$ 
transfection cells group was weaker compared with the control cells. This suggests that the overexpression of $\beta-\mathrm{TrCP}$ inhibits the migration of glioma cells. Invasion is also the main manner of tumor cell movement (36). In the present study, Transwell assay demonstrated that the invasive ability of glioma cells in the $\beta$-TrCP transfection group was decreased compared with the control group. Proliferation is the most important feature of tumor cells. Therefore in the present study, the effect of $\beta$-TrCP on glioma cell proliferation was also observed using EdU assay. The result demonstrated that the proliferative ability of glioma cells was also significantly decreased following $\beta$-TrCP overexpression.

From the above results, it may be hypothesized that $\beta-\operatorname{TrCP}$ protein probably serves as a tumor suppressor to inhibit the growth of glioma. The mechanism may be that $\beta$-TrCP acts on different substrates in glioma cells, but this will require additional investigation.

\section{Acknowledgements}

The present study was supported by the National Natural Science Foundation of China (grant no. 81072072) and a grant from Xuzhou Medical College (grant no. 09KJZ18).

\section{References}

1. Wen PY and Kesari S: Malignant gliomas in adults. N Engl J Med 359: 492-507, 2008.

2. Buonerba C, Di Lorenzo G, Marinelli A, Federico P, Palmieri G, Imbimbo M, Conti P, Peluso G, De Placido S and Sampson JH: A comprehensive outlook on intracerebral therapy of malignant gliomas. Crit Rev OncolHematol 80: 54-68, 2011.

3. Sherman JH, Hoes K, Marcus J, Komotar RJ, Brennan CW and Gutin PH: Neurosurgery for brain tumors: Update on recent technical advances. Curr Neurol Neurosci Rep 11: 313-319, 2011.

4. Onishi M, Ichikawa T, Kurozumi K and Date I: Angiogenesis and invasion in glioma. Brain Tumor Pathol 28: 13-24, 2011.

5. Kim CS, Jung S, Jung TY, Jang WY, Sun HS and Ryu HH: Characterization of invading glioma cells using molecular analysis of leading-edge tissue. J Korean Neurosurg Soc 50: 157-165, 2011

6. Ohgaki H and Kleihues P: Population-based studies on incidence, survival rates, and genetic alterations in astrocytic and oligodendroglial gliomas. J Neuropathol Exp Neurol 64: 479-489, 2005.

7. Rutka JT, Taylor M, Mainprize T, Langlois A, Ivanchuk S, Mondal S and Dirks P: Molecular biology and neurosurgery in the third millennium. Neurosurgery 46: 1034-1051, 2000.

8. Liu C, Kato Y, Zhang Z, Do VM, Yankner BA and He X: beta-Trcp couples beta-catenin phosphorylation-degradation and regulates Xenopus axis formation. Proc Natl Acad Sci USA 96: 6273-6278, 1999.

9. Busino L, Donzelli M, Chiesa M, Guardavaccaro D, Ganoth D, Dorrello NV, Hershko A, Pagano M and Draetta GF: Degradation of $\mathrm{Cdc} 25 \mathrm{~A}$ by beta-TrCP during $\mathrm{S}$ phase and in response to DNA damage. Nature 426: 87-91, 2003.

10. Watanabe N, Arai H, Nishihara Y, Taniguchi M, Watanabe N Hunter T and Osada H: M-phase kinases induce phospho-dependent ubiquitination of somatic Weel by SCF beta-TrCP. Proc Natl Acad Sci USA 101: 4419-4424, 2004.

11. Chiaur DS, Murthy S, Cenciarelli C, Parks W, Loda M, Inghirami G, Demetrick D and Pagano M: Five human genes encoding F-box proteins: Chromosome mapping and analysis in human tumors. Cytogenet Cell Genet 88: 255-258, 2000.

12. Koike J, Sagara N, Kirikoshi H, Takagi A, Miwa T, Hirai M and Katoh M: Molecular cloning and genomic structure of the betaTRCP2 gene on chromosome 5q35.1. Biochem Biophys Res Commun 269: 103-109, 2000.

13. Ballarino M, Marchioni M and Carnevali F: The Xenopus laevis beta $\operatorname{TrCP}$ gene: Genomic organization, alternative splicing, $5^{\prime}$ and $3^{\prime}$ region characterization and comparison of its structure with that of human beta TrCP genes. Biochim Biophys Acta 1577: 81-92, 2002.
14. Deshaies RJ: SCF and Cullin/Ring H2-based ubiquitin ligases. Annu Rev Cell Dev Biol 15: 435-467, 1999.

15. Fuchs SY, Spiegelman VS and Kumar KG: The many faces of beta-TrCP E3 ubiquitin ligases: Reflections in the magic mirror of cancer. Oncogene 23: 2028-2036, 2004.

16. Cenciarelli C, Chiaur DS, Guardavaccaro D, Parks W, Vidal M and Pagano M: Identification of a family of human F-box proteins. Curr Biol 9: 1177-1179, 1999.

17. DeSalle LM and Pagano M: Regulation of the G1 to S transition by the ubiquitin pathway. FEBS Lett 490: 179-189, 2001.

18. Pickart CM: Mechanisms underlying ubiquitination. Annu Rev Biochem 70: 503-533, 2001.

19. Ciechanover A, Orian A and Schwartz AL: Ubiquitin-mediated proteolysis: Biological regulation via destruction. Bioessays 22: 442-451, 2000.

20. Zhou P: Targeted protein degradation. Curr Opin Chem Biol 9: 51-55, 2005.

21. Hershko A and Ciechanover A: The ubiquitin system. Annu Rev Biochem 67: 425-479, 1998.

22. Maniatis T: A ubiquitin ligase complex essential for the NF-kappaB, Wnt/Wingless and Hedgehog signaling pathways. Genes Dev 13: 505-510, 1999.

23. Sahasrabuddhe AA, Dimri M, Bommi PV and Dimri GP: $\beta$ TrCP regulates BMI1 protein turnover via ubiquitination and degradation. Cell Cycle 10: 1322-1330, 2011.

24. Fuchs SY, Chen A, Xiong Y, Pan ZQ and Ronai Z: HOS, a human homolog of Slimb, forms an SCF complex with Skp1 and Cullin1 and targets the phosphorylation-dependent degradation of IkappaB and beta-catenin. Oncogene 18: 2039-2046, 1999.

25. Hart M, Concordet JP, Lassot I, Albert I, del los Santos R, Durand H, Perret C, Rubinfeld B, Margottin F, Benarous R and Polakis P: The F-box protein beta-TrCP associates with phosphorylated beta-catenin and regulates its activity in the cell. Curr Biol 9: 207-210, 1999.

26. Latres E, Chiaur DS and Pagano M: The human F box protein beta-Trcp associates with the Cul1/Skp1 complex and regulates the stability of beta-catenin. Oncogene 18: 849-854, 1999.

27. Shaik $S$, Nucera $C$, Inuzuka $H$, Gao D, Garnaas $M$, Frechette $G$, Harris L, Wan L, Fukushima H, Husain A, et al: SCF ( $\beta$-TRCP) suppresses angiogenesis and thyroid cancer cell migration by promoting ubiquitination and destruction of VEGF receptor 2. J Exp Med 209: 1289-1307, 2012.

28. Zhong J, Shaik S, Wan L, Tron AE, Wang Z, Sun L, Inuzuka H and Wei W: SCF $\beta$-TRCP targets MTSS1 for ubiquitination-mediated destruction to regulate cancer cell proliferation and migration. Oncotarget 4: 2339-2353, 2013.

29. Margottin-Goguet F, Hsu JY, Loktev A, Hsieh HM, Reimann JD and Jackson PK: Prophase destruction of Emil by the SCF (betaTrCP/Slimb) ubiquitin ligase activates the anaphase promoting complex to allow progression beyond prometaphase. Dev Cell 4: 813-826, 2003.

30. Xu Y, Lee SH, Kim HS, Kim NH, Piao S, Park SH, Jung YS, Yook JI, Park BJ and Ha NC: Role of CK1 in GSK3beta-mediated phosphorylation and degradation of snail. Oncogene 29: 3124-3133, 2010

31. He N, Li C, Zhang X, Sheng T, Chi S, Chen K, Wang Q, Vertrees R, Logrono R and Xie J: Regulation of lung cancer cell growth and invasiveness by beta-TRCP. Mol Carcinog 42: 18-28, 2005.

32. Liang J, Wang WF, Xie S, Zhang XL, Qi WF, Zhou XP, Hu JX, Shi Q and Yu RT: Expression of $\beta$-transducin repeat-containing E3 ubiquitin protein ligase in human glioma and its correlation with prognosis. Oncol Lett 9: 2651-2656, 2015.

33. Li X, Liu J and Gao T: beta-TrCP-mediated ubiquitination and degradation of PHLPP1 are negatively regulated by Akt. Mol Cell Biol 29: 6192-6205, 2009.

34. Gluschnaider U, Hidas G, Cojocaru G, Yutkin V, Ben-Neriah Y and Pikarsky E: beta-TrCP inhibition reduces prostate cancer cell growth via upregulation of the aryl hydrocarbon receptor. PLoS One 5: e9060, 2010.

35. Wan M, Huang J, Jhala NC, Tytler EM, Yang L, Vickers SM, Tang Y, Lu C, Wang N and Cao X: SCF(beta-TrCP1) controls Smad4 protein stability in pancreatic cancer cells. Am J Pathol 166: 1379-1392, 2005.

36. Ruiz P and Günthert U: The cellular basis of metastasis. World J Urol 14: 141-150, 1996. 